\title{
La cuestión animal El Magisterio de la Iglesia católica en el contexto del debate actual
}

\author{
RODRIGO FRÍAS URREA \\ Universidad Metropolitana de Ciencias de la Educación (Chile) \\ rodrigo.frias@umce.com
}

\begin{abstract}
Resumen
En este artículo el autor se propone examinar el estatuto ontológico y moral de los animales en el Magisterio de la Iglesia Católica. Antes de esto, sin embargo, se inscribe el magisterio eclesial en el contexto del debate, ya abierto, sobre 'la cuestión animal', poniendo especial atención en los aportes de la ciencia y, sobre todo, de las distintas corrientes filosóficas que alimentan este debate.
\end{abstract}

Palabras clave: animal, iglesia católica, bioética, ecología.

\section{The animals issue \\ The Magisterium of the Catholic Church in the context of the current debate}

\begin{abstract}
In this article the author proposes to examine the ontological and moral status of animals in the Magisterium of the Catholic Church. Before this, however, the Church's Magisterium falls within the context of the debate, and open on 'animal matter', paying particular attention to the contributions of science and, above all, of the various philosophical currents that feed this debate.
\end{abstract}

Key words: animal, catholic church, bioethics, ecology.

Doctor en Filosofía (Pontificia Universidad Católica de Chile) y Máster en Bioética por el Ateneo Pontificio Regina Apostolorum de Roma, Italia. Profesor de Filosofía Clásica en el Centro de Estudios Clásicos Giuseppina Grammatico Amari de la UMCE y de Ética en la P. U. Católica de Chile. Entre sus publicaciones más recientes se cuentan los artículos "Platón y los orígenes griegos de la biopolítica" (2013) e "Identidad personal y racionalidad práctica en la época de la biopolítica" (2013), así como el libro — publicado por la Unesco y del que es editor-Cultura helenística y cristianismo primitivo. Actualidad de un (des)encuentro (2014). 


\section{Introducción. El problema y el método}

La llamada 'cuestión de los animales' viene ocupando desde hace algunas décadas una importancia creciente, de la mano con el interés, igualmente creciente, por la ecología y la ética del medio ambiente. Se trata, desde luego, de un interés legítimo, en la medida que pone en evidencia una mayor sensibilidad por parte del hombre común —sobre todo por parte de las generaciones más jóvenes - frente al modo actual en que los animales, así como la naturaleza, son tratados. La atención se ha centrado, sobre todo, en la transformación progresiva de los animales en 'materia prima' para el consumo - por ejemplo en la industria alimentaria y los laboratorios farmacéuticos- de los que, por otro lado, el mismo hombre que los mira con sospecha obtiene indudables ventajas (alimentos más baratos y medicamentos más seguros). Es la forma más común en que se cristaliza la 'cuestión animal', y que en la mayor parte de los casos se traduce, casi exclusivamente, en una mayor atención y cuidado hacia los animales domésticos.

Pero también ha habido quienes, a partir de esta mayor sensibilidad por los animales, han comenzado a ocuparse de un modo más activo del problema de las condiciones de vida de los animales sometidos a los modernos modos de producción industrial, y se han propuesto, de frente a lo que les parece una forma moderna de 'esclavitud', la conformación de movimientos en su defensa y de sus 'derechos', al tiempo que promueven su 'liberación'. Para ello se han servido, con bastante éxito, de la rica tradición filosófica que ya previamente existía respecto de la cuestión del 'estatuto ontológico y moral de los animales', pero que ahora se ha reactualizado de la mano de los aportes que se desprenden de las modernas investigaciones en el campo de las ciencias de la vida. Esta segunda forma en que se configura la actual 'cuestión animal' es, obviamente, más sofisticada desde el punto de vista de las ideas y más activa políticamente. Además, no es extraño que se acompañe por alguna forma de vegetarianismo.

La perspectiva que a nosotros nos interesa examinar aquí es la del Magisterio de la Iglesia católica, que también se ha sumado al debate. En cualquier caso, lo ha hecho, como veremos, de un modo particular. Lo importante por ahora es señalar que se trata de un debate al que el Magisterio se suma y que, por lo tanto, ya estaba en curso desde antes. De ahí que me ha parecido que sería más útil, antes de examinar directamente la doctrina del Magisterio católico sobre el estatuto ontológico y moral de los animales, como quien dice en abstracto o aisladamente, comenzar por considerar, con una cierta atención, aquellas 
'corrientes de pensamiento' que ya estaban formando parte del debate sobre la cuestión animal y que ofrecen, así, el específico contexto o telón de fondo en el que viene a inscribirse el discurso magisterial de la Iglesia.

\section{Parte}

\section{La filosofía y sus formas}

La 'cuestión de los animales', he dicho, es un problema actual, es decir, de ocurrencia más o menos reciente, pues sólo en los últimos décadas -a propósito, especialmente, del sometimiento de los animales a los procesos técnicos de producción, alimenticia o farmacéutica, que antes no existían - ha cristalizado esta nueva sensibilidad acerca del modo en que son tratados y, en consecuencia, de la eventual necesidad de reformular, más o menos radicalmente, los términos de nuestra relación con ellos. De modo que antes de la época del predominio de la 'esencia de la técnica moderna' (para emplear la expresión de Heidegger) y, por lo tanto, de la reducción del animal a 'material biológico' para uso industrial, no hubo, en términos estrictos, ni una 'cuestión animal' ni podría haber habido, por lo mismo, un movimiento en su 'defensa' o 'liberación'.

En otros términos, la 'cuestión animal' —con las actuales corrientes de pensamiento que sirven de fundamento a los movimientos animalistas de su defensa o de su liberación- sólo pudo surgir en el contexto de la radical tecnificación de la vida, típica de la modernidad tardía.

Es evidente, sin embargo, que estas actuales corrientes de pensamiento sólo existen con la fuerza intelectual que hoy ostentan, con su capacidad de permear la opinión pública, porque son herederas de una tradición filosófica previa, moderna, a las que han renovado de acuerdo a los progresos de la ciencia y al cambio en los paradigmas ideológicos. Aquéllas, en efecto, son algo así como los 'padres fundadores' de las actuales corrientes de pensamiento, que ya hablaban por primera vez de una 'defensa' de los animales o de su 'liberación' — aunque con escasa resonancia social - al tiempo que ya comenzaba a despuntar el modo moderno de producción industrial que tan directamente afectará la condiciones de vida de los animales.

La modernidad, sin embargo, es una realidad plural. Pues junto a estas primeras corrientes animalistas conoció igualmente otras importantes corrientes de pensamiento que, en lo que se refiere a los animales, no se planteó en absoluto la posibilidad de su liberación. De 
hecho, esta otra modernidad, de tipo mecanicista, es probablemente el momento menos favorable para los animales, porque ni compartió la otra comprensión moderna del animal, de tipo liberacionista, pero tampoco adhería ya a la comprensión previa, de matriz greco-medieval, del animal como un viviente.

Conviene distinguir, por lo tanto, aunque sea de un modo esquemático, las distintas corrientes de pensamiento que concurren al actual debate sobre los animales, que en orden de aparición histórica serían el pensamiento greco-medieval, las dos modernidades (la mecanicista y la proto-liberacionista) y las actuales corrientes de pensamiento. $\mathrm{Y}$ cuyos rasgos distintivos, muy generales, son los que siguen (Frías, 2009).

Elpensamiento greco-medieval. Esta corriente está bien representada por pensadores como Aristóteles y Tomás de Aquino. Sus ideas sobre los animales no son exactamente las mismas — pues pertenecen a distintos universos culturales, y donde, además, el segundo está fuertemente influido por el estoicismo- aunque comparte una comprensión general del problema que permite asociarlas estrechamente. También es correcto hablar aquí de la perspectiva aristotélica-tomista.

Para esta corriente de pensamiento lo fundamental es que los animales son vivientes, es decir, habitantes de un mundo natural ordenado o cosmos, capaces de sentir así como experimentar alguna forma, aunque elemental, de vida mental. Por lo mismo, también son capaces de una cierta forma de previsión del futuro. No son, sin embargo, 'sujetos de su propia vida', al modo que en que sí lo son los 'animales racionales' (Aristóteles) o las 'personas' (Tomás de Aquino), a cuyo servicio han sido puestos o por la naturaleza (Aristóteles) o por Dios, su Creador (Tomás de Aquino). No son, por lo tanto, sujetos morales ni tienen derechos, aunque no es propio de los seres racionales - por respeto a sí mismos - hacerlos sufrir innecesariamente. Su estatuto sería, por ello, el de ser pacientes morales.

Entre los humanos y los animales existen, por lo tanto, claras diferencias. La racionalidad es la más importante de ellas, de la que se desprenden otras como el sentido de la moralidad y de la trascendencia. Los animales, en consecuencia, no tienen ni ética ni religión. Estas diferencias entre los hombres y los animales, sin embargo, no introducen entre ellos una separación infranqueable o hiato que los hiciera mutuamente irreconocibles, como si se trata de dos sustancias impermeables. Aquello que en Aristóteles puede ser descrito como 'la común esfera de lo viviente' — que permite ver la identidad en la 
diferencia - se haya igualmente presente en Tomás de Aquino bajo la forma de lo que podríamos denominar 'la común esfera de lo creado', según lo cual hombre y animal, pese a todas sus diferencias, forman parte de esa polimorfa unidad de sentido que es la Creación.

La modernidad mecanicista. Una cosa notablemente distinta acontece, en cambio, en el contexto de la temprana modernidad, cuando con Descartes la común esfera de lo real se escinde irremediablemente entre una res extensa y una res cogitans. Con Descartes, en efecto, tenemos que los animales son vistos, como nunca antes, como si fueran máquinas, cuyo comportamiento se explica mecánicamente. De manera que así como entre el cuerpo y el alma del hombre no se establece ninguna vinculación de sentido, así mismo, entre el animal y el hombre como 'sujeto pensante' no existe ningún tipo de vínculo orgánico o estructural, precisamente porque el animal no posee alma en tanto es una pura exterioridad vacía. Nada tiene de extraño, por lo mismo, que Descartes vea en los animales autómatas o máquinas que, aunque capaces de sentir dolor, cumplen eficientemente las funciones para las que han sido creados, un poco a la manera de un reloj.

De este modo la clásica idea de la superioridad del hombre respecto del animal se mantiene en la visión de mundo inaugurada por Descartes. Es evidente, sin embargo, que ha cambiado de signo, precisamente porque sólo ahora se ha establecido una verdadera separación entre la naturaleza mecánica de los animales y la naturaleza racional de los seres humanos en tanto sujetos pensantes. Ahora, en efecto, se trata de una distinción que es separación, en la forma específica de un dualismo, que autoriza a ver en los animales simples 'cosas' o 'medios' a las que se podrá tratar del modo que resulte más conveniente a nuestros intereses (según piensa Spinoza) o en relación con las cuales se impondrá a los hombres —que en tanto 'personas', o fines en sí mismos, son los únicos a quienes se debe 'respeto' - el deber, indirecto, de ser compasivos (según piensa Kant).

La modernidad proto-liberacionista. Hasta bien avanzada la modernidad se pensó según este esquema racionalista, de tipo mecanicista que, por primera vez, supuso la reconsideración de los animales de creaturas vivas a cosas. Con el empirismo y el utilitarismo, sin embargo, esta perspectiva sufre un cambio de importantes proporciones, que se acentuará con el concomitante aporte del darwinismo. Se trata, en efecto, de la otra modernidad, la animalista. 
En efecto, con el empirismo emotivista de Hume se produce lo que se podría llamar una 'naturalización del hombre', según la cual éste sería, básicamente, un animal, aunque dotado con facultades intelectuales más finas o sofisticadas. Por lo tanto, las diferencias entre unos y otros, que las hay, ya no serían de 'tipo', como en los paradigmas anteriores, sino sólo de 'grado'. De modo que ambos, hombres y animales, esencialmente similares, compartirían el mismo 'razonamiento experimental', fundamental para la vida práctica, en el que, además, influirían poderosamente pasiones, afecciones y sentimientos que los animales son capaces de comunicarse mutuamente y, así, influir en la configuración de las creencias de las que son tan capaces como los hombres. De ahí que los animales deben ser reconocidos, en pie de igualdad con los hombres, como sujetos morales cuyos intereses deben ser tomados en cuenta.

Lo mismo tenemos en el utilitarismo de S. Mill, que al asumir como criterio decisivo de incorporación a la esfera de la moralidad la facultad de experimentar placer o dolor, piensa que lo correcto es ponderar de igual manera - según una escala única y al margen de la especie de pertenencia del individuo afectado- todos los placeres y dolores que provoca una determinada acción. Pues una vez que se ha declarado que «el placer y la ausencia de dolor son las únicas cosas deseables como fines», lo importante es procurar aquel estado de cosas en la que rija el principio de 'la mayor felicidad para el mayor número' de individuos, sin discriminaciones injustificada (y la especie de pertenencia sería una, quizás la más importante). En consecuencia, lo decisivo desde el punto de vista moral — - según la famosa expresión de Bentham— no es si los distintos seres son capaces de razonar o de hablar sino sólo sin son capaces de sufrir. Y los animales lo son.

Actuales corrientes de pensamiento. Con el empirismo y el utilitarismo el racionalismo cartesiano recibió una dura crítica y, de paso, se configuró de un modo significativo el debate contemporáneo sobre los animales. De hecho, de las principales corrientes relativas a nuestro problema que es posible identificar con claridad en el debate actual (Cortina, 2009; Blasco 2011; Prieto 2008), cuatro me parecen especialmente significativas.

Ante todo, el neoutilitarismo, que, con su defensa de la capacidad de sentir como único criterio de demarcación moral, atrae a muchos de los que, actualmente, se comprometen en la defensa de los animales. Su representante más conocido es Peter Singer, que se aleja del lenguaje de los derechos - porque, a su juicio, resultarían irrelevantes desde el punto de vista de la defensa de los intereses de los seres sentientes- para 
concentrarse en la crítica al 'especieísmo' y, de consecuencia, el principio de la sacralidad de la vida humana. Una de sus tesis más radicales es que ni todos los seres humanos son personas, ni todas las personas son seres humanos (Singer, 2003). Su libro Liberación animal, del año 1975, es probablemente el más influyente en los movimientos animalistas.

Igualmente importante es, además, la corriente deontológica. Es obvio, eso sí, que tiene que tratarse de un neodeontologismo, precisamente en la medida en que esta corriente moral, de matriz kantiana, se ha visto obligado a ampliar el estrecho círculo de las personas de las que Kant excluía, precisamente, a los animales. Para autores como Tom Regan, por ejemplo, se trata de adoptar en relación con los animales el lenguaje de los derechos haciendo de ellos, en un paso previo, 'personas' en el sentido de 'sujetos de su propia vida'. Su proyecto, en este sentido, no es liberacionista sino abolicionista, en la medida en que busca «la total abolición del uso de animales en la ciencia, la total disolución de la agricultura comercial animal y la total eliminación de la caza y el aprovechamiento comercial y deportivo de los animales» (Regan, 1983: 179). Lo que pretende Regan, en este sentido, es alcanzar una comprensión de los animales que deje de verlos como 'objetos' para nuestro uso y abuso, y permita verlos como seres cuya vida resulta valiosa en sí misma, al margen de la utilidad que pueda tener para terceros.

También la teoría contractualista goza, a su vez, de una relativamente amplia resonancia en el debate contemporáneo, así como en la opinión pública. Se inspira en el contractualismo de John Rawls (1995), de acuerdo al cual los principios morales que rigen una sociedad son justos en la medida en que han sido acordados por miembros cuya posición en la sociedad, y la de sus próximos, desconocen porque están cubiertos por un 'velo de ignorancia'. Sólo que como en el caso del deontologismo, aquí se trata de un neocontractualismo en la medida en que ahora se incluyen a los animales dentro de aquellos pacientes morales cuyos interesen otros, los agentes morales, estarían interesados en promover. No hace de los animales, por lo tanto, 'personas' ni ‘sujetos de derechos' (a la manera de Regan), aunque sí, diría, individuos 'protegidos', en analogía a la posición que ocupan aquellos seres humanos — como los deficientes mentales - que respetamos aunque sean incapaces de defenderse a sí mismos. Un buen ejemplo de este neocontractualismo es P. Carruthers (2003).

Por último, está lo que se ha llamado la teoría del deber indirecto para con los animales (Blasco, 2011: 80), según la cual nuestra naturaleza racional, fundamento de nuestra superioridad, nos obligaría al 
cumplimiento de ciertos deberes en relación con los animales, aunque éstos, en sí mismos, no gozan de ningún condición intrínseca que justifique su reclamo. Se trata, como es evidente, de la posición defendida, en términos generales, por autores tan distintos como Tomás de Aquino y Kant, para quienes, en efecto, nuestra relación con los animales tendría una importancia real aunque sólo indirecta, en la medida exacta en que ella sería ante todo un reflejo de nuestro comportamiento, actual o posible, con otros miembros de la especie humana. Se trataría, en este sentido, de un 'especieísmo' abierto, próximo, por lo mismo hasta cierto punto, al neocontractualismo de Carruthers. Su defensa de los animales, sin embargo, resulta más débil que la de aquél, porque no es resultado de una ampliación de la esfera de protección sino sólo de una proyección refleja. Goza de una relativa resonancia en la opinión pública, aunque es fuertemente criticada por los movimientos animalistas a causa de su 'especieísmo'.

\section{El darwinismo y la ciencia moderna}

Existen, en consecuencia, distintas posiciones teóricas, de tipo filosófico, que concurren en el actual debate sobre la 'cuestión de los animales'. Algunas de ellas reeditan posiciones más o menos clásicas en la filosofía moral; otras, en cambio, son más típicamente modernas. Su influencia en el debate, en todo caso, es desigual, tanto desde el punto de vista argumental como desde el mediático.

Es probable, sin embargo, que la teoría moderna que más decisivamente ha influido en el actual debate sobre los animales —se esté o no de acuerdo con sus postulados de base- sea la de Darwin, que con su teoría de la evolución parece ofrecer la prueba definitiva de la sustancial identidad del hombre y del animal y, en consecuencia, sobre la ilegitimidad de establecer discriminaciones por razones de pertenencia a una determinada 'especie' (concepto que, ya en el campo puramente biológico, resulta polémico). Además, la tradicional idea de que sólo el hombre es racional - $\mathrm{y}$, por lo tanto, que sólo él tendría derechos morales- quedaría superada, tal como da a entender el propio Darwin cuando afirma que «el hombre está construido según el plan o modelo general de los otros mamíferos», de modo que, por ejemplo, «no existe ninguna diferencia fundamental entre el hombre y los mamíferos superiores en cuanto a sus facultades mentales» (Darwin, 2009: 45).

Su decisiva influencia en el debate sobre la 'cuestión animal', sin embargo, no se explica única ni principalmente por sus postulados o hipótesis científicas —que en sí mismas parecen bastante correctas, 
aunque haya aspectos por precisar- sino, sobre todo, por las proyecciones que se hicieron a partir de ella, ya por el propio Darwin, hacia campos meta-científicos, como la ética y la religión o, más en general, hacia el de la 'naturaleza' humana. Es decir, debido a su rápida transformación en una mentalidad, que cabe llamar darwinismo, cuyos postulados metafísicos sobre la 'naturaleza' del hombre -imposible, por lo mismo, de someter a la lógica de la verificación experimental- han sido asumidos, en casos extremos, como si se tratara de verdaderos artículos de una fe religiosa (Prieto, 2008: 20-22). Una mentalidad, por lo tanto, que defiende no tanto la teoría de la evolución sino el evolucionismo, que niega todo finalismo y atribuye todo a la casualidad (Pascual, 2005). Para el filósofo norteamericano Charles Ruse, por ejemplo, en la adopción de los postulados darwinistas estaría en juego «la última ruptura con las creencias tribales de Occidente» deudoras de «una forma de judeocristianismo que ve al ser humano como algo especial, construido a imagen y semejanza divina, y cree que todo ello exige fuerzas creadoras también especiales» (Ruse, 2008: 195-196). De ahí que concluya que «si alguien cree en Dios y en la posibilidad que haya milagros de cualquier tipo, esas creencias no forman parte de los debates [generales, se entiende, y no sólo los debates científicos, en cuyo caso la restricción es completamente legitima] sobre la naturaleza de la humanidad ni sobre sus orígenes» (Ruse, 2008: 181). Para la mentalidad darwinista o evolucionista, en otras palabras, una teoría biológica como la de Darwin, aunque manipulada ideológicamente, sería la única autorizada a pronunciarse sobre quienes pueden debatir acerca de la verdadera estructura metafísica de la 'naturaleza' humana. Quizás tenga razón Popper, en este sentido, cuando piensa que la teoría de Darwin no es una teoría científica en sentido estricto sino «un programa metafísico de investigación que proporciona un cuadro de referencia a teorías científicas controlables» (Popper, 1985: 230).

Entre tanto, las ciencias de la vida han avanzado notablemente en el estudio comparado de la estructura biológica del cuerpo humano, de acuerdo con el cual entre el animal (chimpancés y primates en general) y el humano existe una casi total identidad genética; sólo que ese casi, distintivo de la humanidad del ser humano constituiría el fundamento biológico de unas diferencias que no serían sólo de grado. Es lo que puede apreciarse en las dos tablas que siguen, en las que se resume en resultado de las actuales investigaciones científicas (Blasco, 2011: 40-41). 
Diferencias entre humanos y animales

\begin{tabular}{|c|c|c|}
\hline & Animal & Humano \\
\hline Genes & $\begin{array}{l}\text { El chimpancé comparte un } 99 \\
\text { por } 100 \text { con los humanos. }\end{array}$ & $\begin{array}{l}\text { Comparte un } 99 \text { por } \\
100 \text { con los } \\
\text { chimpancés. }\end{array}$ \\
\hline Lenguaje & Carece de sintaxis. & $\begin{array}{l}\text { Sintaxis con futuro, } \\
\text { pasado, preguntas y } \\
\text { referencias simbólicas. } \\
\text { Recursividad. }\end{array}$ \\
\hline $\begin{array}{l}\text { Creación de } \\
\text { instrumentos }\end{array}$ & $\begin{array}{l}\text { No elaborados; p. ej., los } \\
\text { instrumentos elaborados por } \\
\text { cuervos o chimpancés. }\end{array}$ & $\begin{array}{l}\text { Elaborados, con } \\
\text { 'propiedades } \\
\text { emergentes'. Los } \\
\text { guarda y los } \\
\text { perfecciona. }\end{array}$ \\
\hline $\begin{array}{l}\text { Transmisión } \\
\text { cultural }\end{array}$ & $\begin{array}{l}\text { Imitativa o por focalización de la } \\
\text { atención; p. ej., como la de los } \\
\text { pinzones o los loros. }\end{array}$ & $\begin{array}{l}\text { Creativa y acumulativa. } \\
\text { Incluye elementos } \\
\text { simbólicos y } \\
\text { 'consciencia del otro'. }\end{array}$ \\
\hline Ética & Carece de ética. & $\begin{array}{l}\text { Arte simbólico } \\
\text { (adornos). Arte } \\
\text { 'gratuito' (sin objetivo } \\
\text { de supervivencia). } \\
\text { Cree que hay 'deberes' } \\
\text { para con los otros. }\end{array}$ \\
\hline Religión & Carece de religión & Fenómeno religioso \\
\hline Altruismo & $\begin{array}{l}\text { Muestra altruismo con ventaja } \\
\text { evolutiva; p. ej., muchos pájaros } \\
\text { arriesgan su vida por la } \\
\text { descendencia. }\end{array}$ & $\begin{array}{l}\text { Muestra altruismo sin } \\
\text { ventaja evolutiva } \\
\text { aparente; p. ej., cuidado } \\
\text { de minusválidos con } \\
\text { genes prejudiciales. }\end{array}$ \\
\hline Sufrimiento & $\begin{array}{l}\text { Siente dolor. No padece } \\
\text { 'sufrimiento emocional', salvo, } \\
\text { tal vez, los primates superiores. }\end{array}$ & $\begin{array}{l}\text { Siente dolor. Es } \\
\text { consciente del dolor. } \\
\text { Padece sufrimiento } \\
\text { emocional. }\end{array}$ \\
\hline Autoconsciencia & $\begin{array}{l}\text { No muestra signos de } \\
\text { autoconsciencia, salvo } \\
\text { fenómenos elementales como } \\
\text { reconocerse en un espejo } \\
\text { (chimpancés, cetáceos, elefantes } \\
\text { y urracas). }\end{array}$ & $\begin{array}{l}\text { Sabe que va a morir. } \\
\text { Tiene proyectos de } \\
\text { futuro. Gobierna su } \\
\text { vida. Asume los } \\
\text { intereses del otro en la } \\
\text { cooperación. }\end{array}$ \\
\hline Cerebro & $\begin{array}{l}\text { No tiene córtex prefrontal o, si } \\
\text { lo tiene (simios superiores), está } \\
\text { escasamente desarrollado. }\end{array}$ & $\begin{array}{l}\text { Tiene un córtex } \\
\text { prefrontal desarrollado. }\end{array}$ \\
\hline
\end{tabular}


Secuencias de ADN diferentes entre chimpancés y humanos

\begin{tabular}{|l|l|}
\hline Secuencia & \multicolumn{1}{c|}{ Efecto } \\
\hline HAR1 & Desarrollo del córtex, que nos distingue de los chimpancés. \\
FOXP2 & $\begin{array}{l}\text { Permite movimientos faciales que facilitan el habla. } \\
\text { Facilita la digestión de almidón, lo que permite tener acceso a } \\
\text { nuevos alimentos. }\end{array}$ \\
ASPM & $\begin{array}{l}\text { Controla el tamaño del cerebro } \\
\text { Permite a los adultos la digestión de los azúcares de la leche, lo }\end{array}$ \\
& $\begin{array}{l}\text { que da acceso a un nuevo alimento proveniente de animales } \\
\text { domesticados. } \\
\text { Está relacionado con la formación de la muñeca y el pulgar } \\
\text { humanos; facilita la destreza manual típica de los humanos. }\end{array}$ \\
\hline
\end{tabular}

\section{Parte}

\section{El Magisterio católico en el debate en torno a la cuestión animal}

Son múltiples los elementos que concurren en el actual debate sobre la cuestión animal, desde filosóficos a científicos, pasando por otros claramente ideológicos. Además, existe una opinión pública cada vez más interesada en esta cuestión, al tiempo que más proclive a una defensa más explícita y concreta de los animales. El Magisterio de la Iglesia católica viene, por lo tanto, a incorporarse a un debate no sólo amplio sino polémico, en cuyo seno hay quienes incluso piensan, como hemos podido apreciar, que la intervención de la Iglesia en estas materias sería ilegítima; es decir, piensan que este debate sobre el hombre y el animal sería sólo asunto de discursos 'racionales' (en el sentido en que ellos, naturalmente, han definido previamente qué ha de entenderse por 'racional'). Es importante, por lo mismo, todavía antes de conocer qué dice sobre el estatuto ontológico y moral de los animales, apreciar qué tipo de intervención es el que, formalmente, se propone hacer el Magisterio. Tres observaciones me parecen fundamentales.

Naturaleza de su intervención. La primera, que se trata de una intervención teológica, es decir, racional, que se apoya, siempre críticamente, en la filosofía y en las ciencias de la naturaleza, cuya autonomía respeta, pero que no es ni lo uno ni lo otro. Ella, en efecto, tiene como suelo o fundamento último las verdades de la fe, sobre las que reflexiona según una metodología que le es propia (Juan Pablo II, 1998: n.65; cf. Ratzinger, 2002). La doctrina magisterial, en este sentido, viene a inscribirse en el debate sobre la cuestión de los animales porque conserva 
su identidad teológica, no a pesar de ella. Es absolutamente legítimo, por lo tanto, que el Magisterio de la Iglesia católica, qua magisterio católico, se pronuncie y entre a formar parte de este debate sobre la 'cuestión animal', así como sobre la 'naturaleza de la humanidad y de sus orígenes'. Pues lo hace con el mismo derecho con que lo hace la racionalidad filosófica y la racionalidad científica, es decir, como racionalidad teológica.

La segunda, que la relación que el Magisterio mantiene con la tradición filosófica es fundamental e imprescindible para su propio ejercicio reflexivo y de clarificación (Juan Pablo II, 1998: n.64), pero excluye, de manera explícita, la existencia de una filosofía católica oficial. Se trata, en efecto, de una intervención racional y autónoma, que se apoya, por lo tanto, en sus propios fundamentos (especialmente bíblicos). El Magisterio lo ha dicho con claridad: «la Iglesia no propone una filosofía propia ni canoniza una filosofía en particular con menoscabo de otras» (Juan Pablo II, 1998: n.49). Es perfectamente legítimo, en este sentido, que el Magisterio se aproxime más a una filosofía que a otra sin que, por ello, debamos pensar que se trata de una simple identificación. De hecho también podría, en principio, aproximarse a otras, más nuevas o menos tradicionales, y obtener de allí, con provecho, nuevas posibilidades de clarificación del mensaje bíblico. Dicho de otro modo: el Magisterio, formalmente, no entra en el debate actual como simple vocera de alguna de las filosofías que ya concurren a ese mismo debate — por importantes que hayan sido, hasta ahora, sus puntos de coincidencia, como de hecho ocurre con la filosofía de Tomás de Aquino- sino que lo hace conservando la independencia que se desprende de su especificidad teológica así como de su inspiración bíblica.

Y la tercera, que es esa misma posición de independencia de la reflexión Magisterial respecto de las teorías filosóficas y científicas es la que justifica su deber de examinarlas atentamente para discernir en ellas, a la luz de las verdades de la fe, aquello que se contrapone a la doctrina cristiana. Se trata, diría, de una intervención crítica con fines evangelizadores. De modo que aunque respeta la esfera de autonomía propia de cada disciplina, tiene al mismo tiempo el deber de aclarar aquello que en ellas, o que se deriva de ellas, puede resultar incompatible con la fe. Dicho en otro términos, el Magisterio no entra en el debate sobre la 'cuestión animal', como en ningún otro, para adherir, más o menos abiertamente, a unos determinados postulados científicos o filosóficos ni, mucho menos, para ser un simple espectador pasivo; lo hace, en cambio, para exponer, según la metodología científica que le es propia, la Verdad que le ha sido encomendada custodiar. 


\section{Características de su intervención}

La intervención del Magisterio en el debate de la cuestión animal posee una autonomía que parece justificarla plenamente. Es expresión de una legítima racionalidad teológica, es autónoma y responde con coherencia a sus propósitos evangelizadores.

¿Cuáles son, entonces, las principales ideas y conceptos sobre la cuestión animal que encontramos en el Magisterio de la Iglesia católica y, sobre todo, cómo se articulan estas ideas en el contexto del actual debate?

Una cuestión subordinada. Lo primero que cabe señalar es que la cuestión animal no ocupa, ni mucho menos, el centro de las preocupaciones bioéticas del Magisterio católico. En efecto, el problema relativo al estatuto ontológico y ético de los animales no es abordado in extenso en los Documentos del Magisterio de la Iglesia Católica sobre Bioética porque, en palabras del Papa Juan Pablo II, la bioética se ocupa, ante todo, de los «problemas éticos, incluso fundamentales, que afectan a la vida del hombre» (Juan Pablo II, 1995: n.27; cf. Frías, 2004); de modo que cuando el Magisterio aborda la 'cuestión animal' —en las poquísimas ocasiones en que ello ocurre- lo hace, formalmente, a propósito de los problemas éticos que afectan a la vida del hombre; es decir, como una parte, subordinada, de su bioética humanista. Así, cuando se interroga, por ejemplo, sobre los límites de la experimentación científicas en los animales, lo hace, sobre todo, para que resulte más evidente su diferencia en relación con la naturaleza humana y su dignidad; en consecuencia, lo hace con un interés indirecto. El Magisterio, en síntesis, se incorpora al debate sobre la 'cuestión animal' a propósito de la 'cuestión del hombre', es decir, en el marco de una reflexión sobre la dignidad de la persona humana, no en razón de un interés por el animal mismo. Su perspectiva, por lo tanto, es bumanista, aunque de carácter teocéntrica (para el concepto de bumanismo que aquí adopto, véase, Heidegger, 2000).

Para hacerse una idea más o menos sistemática del juicio del Magisterio sobre la cuestión animal, por lo tanto, es necesario completar lo poco que se dice sobre los animales en los documentos suyos sobre bioética (Sarmiento, 1996) recurriendo a lo, igualmente, poco que se dice en otros textos, como aquellos en que se ocupa de los problemas económicos relativos al uso legítimo de los recursos naturales, además del Catecismo. Conviene no perder de vista, sin embargo, que en todos ellos rige, sin excepción, la misma perspectiva bumanista. 
Puede resultar un poco decepcionante este interés puramente indirecto por los animales $\mathrm{y}$, en consecuencia, lo escueto de sus testimonios. Contrasta, en todo caso, con la notable cantidad de textos dedicados a este problema por corrientes de pensamiento, como el utilitarismo y el neodeontologismo que, aunque desde distintos puntos de vista, coinciden en poner en igualdad de condiciones (de intereses o de derechos, respectivamente) hombres y animales.

Existen razones, evidentemente, que explican esta desigual atención a la 'ecología natural' y a la 'ecología humana', para usar la expresión empleada por Juan Pablo II (1991: nn.37-38).

Está, en primer lugar, el relato bíblico del Génesis que, en medio de juicios positivos y respetuosos respecto de los animales, no deja la menor dudar acerca de la superioridad del hombre —creado a imagen y semejanza de Dios - respecto del animal. Parece normal, en consecuencia, que el discurso magisterial se centre en la vida del hombre, sin ser por ello un discurso antropocéntrico (Ratzinger, 2002: 39-73). Que esta perspectiva sea normal, sin embargo, no quiere decir que sea necesaria, pues es perfectamente posible que - a partir de estos mismos esos elementos veterotestamentarios, así como del mensaje evangélico acerca de la renovación cósmica, y no puramente personal, que trajo consigo la resurrección de Cristo- se construyera una teología alternativa o, al menos, complementaria, a la tradicional, en la que la 'vida no personal', es decir, todo el orden de la naturaleza, constituya un foco de atención valiosa por sí misma (Linzey, 1996).

Tiendo a pensar, por todo esto, que lo que realmente ha determinado la orientación humanista, siempre en clave teocéntrica, del discurso magisterial sobre los animales, adoptando hacia ellos un interés tan escaso e indirecto, no han sido tanto los datos bíblicos en sí mismos sino, más bien, la clave de lectura filosófica que se ha aplicado a ellos; en concreto, la que deriva de la perspectiva de Tomás de Aquino, que —aunque comparte, como señalamos oportunamente, la visión clásica del animal como de un 'viviente' que forma parte de la 'esfera de lo creado', de modo que el animal no es ni una 'cosa' ni una 'máquina'lleva, sin embargo, el discurso de la diferencia entre el hombre y el animal a extremos, hoy por hoy, difíciles de justificar, en los que la dignidad de aquel se opone radicalmente a la insignificancia moral del éste.

Es significativo, en todo caso, el hecho que el Magisterio, aun cuando se articula según el razonamiento tomista, ya no usa algunas de sus expresiones más radicales. En ninguno de sus documentos habla, en concreto, de los animales como de 'esclavos' a los cuales se les puede dar 
muerte de un modo prácticamente impune (Aquino, 2007: II-II, q.64, a.1).

El animal forma parte de la Creación. Que la cuestión animal sea un problema subordinado, de modo que el estatuto ontológico y moral del animal parece importar sólo a propósito del problema de la dignidad del hombre, no impide, sin embargo, que el Magisterio afirme de modo consistente que el animal forma parte de la Creación; es decir, que posee una naturaleza, que al ser buena de suyo merece aprecio y benevolencia por parte de los hombre. Se trata, en efecto, de dos tesis perfectamente compatibles. El Catecismo lo sintetiza así: «Los animales son criaturas de Dios, a las que rodea Él de su solicitud providencial (cf. Mt 6, 16). Por su simple existencia, lo bendicen y le dan gloria (cf. Dn 3, 57-58). También los hombres le deben aprecio» (n.2416). Y más adelante: «Los animales están confiados a la administración del hombre que les debe benevolencia» (n.2457).

En este sentido, pienso que lo que Juan Pablo II dice sobre la tierra se puede aplicar perfectamente al animal: «Cree [el hombre que se deja llevar por su egoísmo] que puede disponer arbitrariamente de la tierra, sometiéndola sin reservas a su voluntad como si ella no tuviese una fisonomía propia y un destino anterior dados por Dios, y que el hombre puede desarrollar ciertamente, pero que no debe traicionar. En vez de desempeñar su papel de colaborador de Dios en la obra de la creación, el hombre suplanta a Dios y con ello provoca la rebelión de la naturaleza, más bien tiranizada que gobernada por él» (Juan Pablo II, 1991: n.37). De ahí que se pueda hablar, incluso, del 'respeto' que esas realidades naturales exigirían al hombre, de modo que convendría «tomar mayor conciencia de que no se pueden utilizar impunemente las diversas categorías de seres, vivos o inanimados —animales, plantas, elementos naturales- como mejor apetezca, según las propias exigencias económicas. Al contrario, conviene tener en cuenta la naturaleza de cada ser y su mutua conexión en un sistema ordenado, que es precisamente el cosmos» (Juan Pablo II, 1987: n.34; además, Juan Pablo II, 1995: n.42, donde habla del «respeto» a la vida, «de toda vida»).

De nuevo, existen abundantes fundamentos bíblicos para esta afirmación. Basta con leer con atención el primer relato de la creación en el Génesis (1,24-30), para advertir hasta qué punto el Cristianismo está, formalmente, muy lejos de ser una 'visión de mundo' que favorecería la explotación indiscriminada de la Tierra, incluido los animales. Es cierto que en el pasaje del Génesis se habla de 'mandar' y someter', pero se trata de un dominio que, a imitación del dominio de Dios sobre todo lo 
creado, tiene por finalidad la 'custodia' de lo dominado (Gn 3,15). Es un dominio de creación, no de destrucción, tanto que el hombre original es vegetariano; no es extraño, en consecuencia, que el hombre y el animal aparezcan especialmente vinculados, por el alimento que comparten, a la manera de hermanos (Pikaza, 2006: 35). No es banal observar, en este sentido, que el hombre sólo está autorizado a comer la carne de los animales a los que da muerte después del pecado, no antes, «como si fuera una especie de concesión al clima de 'violencia' que distingue a la condición humana después del pecado de los orígenes» (Tettamanzi, 2002: 169), pero que debiera cesar ya con el sacrificio de Cristo, que libera, renovándola, a toda la creación, incluyendo a los animales (San Pablo, Carta a los romanos 8,20-21; Apocalipsis, 21,5). La imagen bíblica del hombre original es la de quien domina benévolamente; la del animal, la del hermano menor. La misma idea aparece en el Evangelio, cuando Jesús —el cordero de Dios que, sin embargo, no era vegetariano- exhorta a los hombres a cuidar a los animales incluso en sábado $(M t 12,11)$.

La filosofía tradicional, de la que se nutre fuertemente el discurso magisterial, también insiste en el carácter de viviente de los animales, cuya vida está perfectamente integrada, con la del hombre, en la 'esfera' de lo natural (Aristóteles) o de la 'creación' (Tomás de Aquino). Por lo tanto, y a diferencia de lo que afirmará una parte importante del pensamiento moderno (el modelo racionalista, que incluye a Descartes, Spinoza y Kant), no se trata de una 'cosa' o 'máquina', carente de cualquier forma de interioridad y cuyo sentido, de uso o función, le haya sido inicialmente atribuido por el hombre — señor absoluto y despótico del mundo— ni, menos aún, un simple 'dispositivo' dispuesto para su explotación arbitraria.

Es interesante notar, en todo caso, que el aprecio y la benevolencia de los que habla el Catecismo, así como el respeto del que habla Juan Pablo II, es decir, el reconocimiento del valor objetivo o intrínseco que tendría el animal como viviente, parecen estar más cerca de la cordialidad de Francisco de Asís que del intelectualismo de Tomás de Aquino. Me parece que no es casualidad, en este sentido, que el Catecismo (n.2416) nombre al 'pobre de Asís' (junto a Felipe Neri), y no al aquinate, como ejemplo del delicado trato debido a los animales.

El animal no es una persona. Tenemos, entonces, que la primera, y fundamental, afirmación del Magisterio católico sobre el animal es que éste forma parte de la Creación, de modo que posee una naturaleza propia. Esto no quiere decir, sin embargo, que esa vida propia que tiene el animal él se la haya, además, apropiado. Tener una vida propia y 
apropiársela son cosas distintas, que en el animal no coinciden (o si lo hacen, es siempre en un grado muy bajo y de modo excepcional). Los animales, para decirlo brevemente, no son personas, como sí lo son, en cambio, los seres humanos, que, según declara el Catecismo (n.357), «no es solamente algo, sino alguien, capaz de conocerse, de poseerse y de darse libremente y de entrar en comunión con otras personas» (véase Spaemann, 2000). Esta es la segunda tesis fundamental del Magisterio sobre los animales.

Por supuesto que en la Biblia no se dice, explícitamente, que el animal no es una persona. Tampoco se dice que el hombre lo sea, aunque es evidente que el contenido del concepto de 'persona' —usado ampliamente en la teología del cristianismo primitivo al ocuparse del problema de la naturaleza de Cristo - se refiere a aquella condición ontológica que, según la Biblia, diferencia a los hombres de los animales (Milano, 1996).

También la idea que el animal no es una 'persona' es sostenida por una parte importante de la tradición filosófica occidental (Boecio y Tomás de Aquino y, desde presupuestos argumentales distintos, Kant), así como por una parte de las actuales corrientes de pensamiento (el neocontractualismo de Carruthers). Neoutilitaristas como Singer y neodeontologistas como Regan, en cambio, a partir de un concepto alternativo de persona, inspirado en Hume, defienden el carácter de persona de los animales, o al menos de algunos de ellos. Persona es, en cualquier caso, uno de los conceptos clave de la discusión sobre el estatuto ontológico y moral de los animales, que se usa, además, siempre como un sentido positivo.

El concepto de persona que usa el Magisterio, en todo caso, resulta muy próximo al usado por Tomás de Aquino —que sigue, a su vez a Boecio - aunque aquí tenga sobre todo un sentido por negación: el concepto de 'persona' nos permite saber lo que el animal no es. El problema de fondo, sin embargo, consiste en saber, positivamente, qué es el animal. Es una cuestión fundamental, aunque difícil (Heidegger, 2007: 257).

Según la argumentación desarrollada más arriba, en relación al carácter de viviente del animal, defendí la tesis según la cual el Magisterio afirmaría que el animal es una 'cosa' o un 'algo' sino que es, precisamente, un 'viviente'. La tesis del Magisterio sería, a la luz estos textos, que el animal no es una 'persona', pero tampoco es una 'cosa' porque posee el carácter de 'viviente'. De modo que, según esta argumentación, habría tres tipos de realidades: las personas (los humanos), los vivientes (animales, plantas) y las cosas. Sólo que, ahora de 
acuerdo a la argumentación del Catecismo n.357, parece que sólo existen o cosas o personas; de modo que si tomamos como punto firme lo que se dice explícitamente, es decir, que sólo el hombre es personal y el resto, en cambio, es sólo un cosa, tendríamos al final que admitir que también el animal, un 'viviente', no es más que una 'cosa'. ¿Son lo mismo, sin embargo, 'viviente' y 'cosa'?

Me parece evidente, en cualquier caso, que aquí hay una indefinición, quizás voluntariamente buscada, en la posición magisterial, que se vuelve a poner de manifiesto en otro texto, esta vez tomado de la Instrucción Donum vitae. A propósito del problema del estatuto ontológico y moral del cuerpo humano, se afirma, en efecto, que «el cuerpo humano no puede ser reducido a un complejo de tejidos, órganos y funciones, ni puede ser valorado con la misma medida que el cuerpo de los animales, ya que es parte constitutiva de una persona, que a través de él se expresa y se manifiesta» (Congregación para la Doctrina de la Fe, 1987: n.3; además, Juan Pablo II, 1995: n.23; Catecismo, n.362). Es evidente que se opone el cuerpo humano al cuerpo animal, para mostrar el carácter personal del primero. Es claro, por lo tanto, que el cuerpo animal no es un cuerpo personal. De nuevo sabernos lo que el animal no es. Lo que no queda tan claro, sin embargo, son dos cosas: primero, si el animal se identifica con su cuerpo, en el sentido de ser ese cuerpo, y nada más; y segundo, si ese cuerpo animal, que sería el animal mismo, se puede identificar con ese 'complejo de tejidos, órganos y funciones', que también podría ser la descripción de una 'cosa' (viva y más compleja, pero finalmente una cosa). El texto, en mi opinión, es ambiguo o impreciso (quizás, como el del n.357 del Catecismo, de un modo consciente), aunque por el tono general de la argumentación tiendo a pensar que el Magisterio está afirmando no sólo que el animal se agota en su cuerpo sino que ese cuerpo-animal, al no ser personal, tiene necesariamente el carácter de 'cosa' (véase, Congregación para la Doctrina de la Fe, 1987: n.4).

El animal está al servicio justo del hombre. El animal, entonces, es una creatura de Dios, que posee una naturaleza propia, dada por Dios, y que, en principio, merece 'respeto', 'aprecio', 'benevolencia' y a la cual, incluso, se puede 'amar' (aunque de un modo distinto, inferior diríamos, al 'amor' debido a otro ser humano [Catecismo, n.2418]). No es, sin embargo, una persona; por lo tanto, es perfectamente legítimo usarlos aunque no de un modo arbitrario o por razones frívolas. El Catecismo (n.2457) habla, concretamente, de los animales al servicio de la justa satisfacción de las necesidades del hombre. 
Desde el punto de vista del Magisterio, entonces, tendríamos ciertos deberes hacia los animales, cuyo cumplimiento sería obligatorio moralmente hablando: de modo que podemos usarlos pero no debemos hacerlos sufrir inútilmente ni sacrificar sin necesidad sus vidas (Catecismo, n.2418). No queda claro, sin embargo, dónde se establece la línea que diferencia un sufrimiento inútil de uno que no lo es, así como tampoco respecto de lo que ha de entenderse por sacrificio 'innecesario'. Más importante, sin embargo, es que tampoco queda claro cuál es la naturaleza de esos deberes, así como el fundamento de su obligatoriedad.

Una alternativa es pensar que se trataría de deberes directos. Pienso, en efecto, que el propio Magisterio católico, al hablar de la posesión, por parte de la naturaleza, de 'una fisonomía propia y un destino anterior dados por Dios', así como de la necesidad de 'respetar la naturaleza de cada ser' y de 'apreciar' a los animales, tratándolos con 'benevolencia' e, incluso 'amándolos', aludiría a un fundamento objetivo, propio de los animales, sobre los cuales se apoyaría, a posteriori, el reconocimiento por parte del hombre. De modo que el animal podría llegar a ser receptor pasivo de un aprecio benevolente sólo porque él mismo, de suyo, es decir, de un modo activo, poseería ya ese estatus ontológico y moral de 'creatura de Dios' que lo hace posible y, a la larga, lo exigiría.

La otra posibilidad, en cambio, es pensar en la teoría de los deberes indirectos. Es la que el Magisterio privilegia explícitamente, cuando afirma que los deberes hacia los animales vienen exigidos por el respeto que el hombre se debe a su propia dignidad (es decir, hacia sí mismo como hacia otros seres humanos, presentes o futuros), no como expresión de un respeto hacia los animales en sí mismos (véase, Catecismo, n.2415-2418 y Juan Pablo II, 1991: n.38).

Los fundamentos bíblicos ofrecen una justificación posible tanto para una como para la otra opción interpretativa - basta comparar el distinto estatuto de los animales en Gn 1 y 2 con Gn 9,1-7- aunque, quizás, por razones de caridad evangélica y escatológicas, habría que inclinarse por la teoría de los deberes directos, como seguramente habría preferido Francisco de Asís, ejemplo, ya referido, del modo correcto de relacionarse con los animales (Catecismo, n.2416).

La tradición filosófica clásica, en cambio, se ha pronunciado muy ampliamente a favor de los deberes indirectos (Kant, Carruthers), con el caso extremo de la justificación que ofrece Tomás de Aquino (2007: I-II, q.102, a.6, ad.8). El neoutilitarismo (Singer) no niega la posibilidad que los animales puedan servir a los hombres, aunque piensa que es una cuestión que debe evaluarse en cada caso según lo intereses que estén en juego. El neodeontologismo de Regan, en cambio, lo niega de plano 
porque el animal no es un medio sino un fin en sí mismo, con derechos inalienables. El Magisterio, en cualquier caso, asume la perspectiva tomista, aunque expresada en un lenguaje que ha superado su frío humanismo intelectualista.

\section{Consideración final}

La doctrina magisterial sobre los animales puede resumirse así: el animal es una realidad 'viva' que, como tal, forma parte del orden natural de la Creación. No es, sin embargo, una 'persona', de modo que puede ser usada por el hombre, aunque con los límites que éste se autoimpone por respeto a su propia dignidad. En síntesis: para un Magisterio humanista, centrado en la dignidad de la persona humana, el animal tiene sólo un interés indirecto o reflejo.

Algunas de estas afirmaciones o principios el Magisterio católico las comparte con otras corrientes de pensamiento, tanto tradicionales como actuales. Por ejemplo, está relativamente próximo al deontologismo kantiano y al neocontractualismo de Carruthers, así como en las antípodas del utilitarismo de Singer. Resulta evidente, sin embrago, su esencial afinidad con el realismo personalista, en su versión aristotélicotomista (Sgreccia, 2000: 60). Todo ello es perfectamente normal, y está lejos de inhabilitar al Magisterio católico a tomar parte en el actual debate sobre la cuestión animal.

Lo que sí, en cambio, constituye una desventaja para el propio Magisterio, en el contexto del competitivo debate actual, es que sus juicios sobre los animales resultan, comparativamente, demasiado breves y esquemáticos como para ser plenamente satisfactorias. Su principal problema radica, dicho de otro modo, no en lo que el Magisterio dice acerca de los animales sino en el modo en que lo hace. Sería deseable, en consecuencia, que el Magisterio católico avanzara hacia una reflexión más amplia y, sobre todo, más enfocada en el problema específico de qué es un animal y cuál es su estatuto moral.

No se trata, sin embargo, de un asunto fácil, porque para que el animal se transforme en un tema en sí mismo interesante de tratar, es necesario que, antes, él mismo adquiera una centralidad que, desde el punto de vista del personalismo realista, no tiene ni podría tener. En otras palabras, para que comenzara a haber una reflexión magisterial centrada en el animal $\longrightarrow \mathrm{y}$ no sólo a propósito de otras realidades, más importantes que el animal— sería necesario que ese mismo Magisterio se abriera a otros modelos de reflexión, existentes al interior del propio 
cristianismo, que sí parecen ofrecen el espacio necesario para esa postergada aparición del animal. Pienso, en términos muy concretos, que sería muy fructífero si el frío intelectualismo tomista se atemperara, por ejemplo, con la benevolencia caritativa del franciscanismo, de modo que no sólo se empezara a redescubrir el rostro fraterno de los animales sino, además, se hiciera evidente la radicalidad liberadora propia del espíritu evangélico, que ha venido a renovar a toda la Creación.

El Magisterio necesita establecer una mayor sintonía con el hombre de hoy y su sensibilidad más favorable hacia los animales. No existe ninguna razón, sin embargo, que justifique que, para alcanzar ese propósito legítimo, el Magisterio tuviera que ceder a las filosofías de moda que elevan al animal al precio de rebajar al hombre. No se trata, obviamente, de eso. Más fructífero es, en lo inmediato, comenzar por desenmascarar los prejuicios ideológicos y las tendencias de intolerancia, incubadas en la propia secularización, que se oponen a que la Iglesia participe activamente en este debate. Pienso, sin embargo, que lo que sí constituiría un verdadero punto de giro en estos esfuerzos por hacer más atractivo su mensaje, sería que el Magisterio - en una muestra de esa sabiduría que la caracteriza - se abriera con decisión a la riqueza de las múltiples formas del pensamiento cristiano, que sobre el animal tienen, seguramente, mucho que decir.

\section{REFERENCIAS}

-Aquino, T. de (2007). Suma de Teología (5 Vols.). Madrid: BAC.

-Blasco, A. (2011). Etica y bienestar animal. Madrid: Akal.

-Carruthers, P. (2003). La cuestión de los animales. Cambridge: Cambridge University Press.

-Congregación para la Doctrina de la Fe (1987). Instrucción 'Donum vitae'. En A. Sarmiento (Ed.) (1996). El don de la vida. Documentos del Magisterio de la Iglesia sobre Bioética (págs. 517-564). Madrid: BAC.

-Cortina, A. (2009). Las fronteras de la persona. El valor de los animales, la dignidad de los bumanos, Madrid: Taurus.

-Darwin, Ch. (2009). El origen del hombre. Barcelona: Crítica.

-Frías, R. (2009). Ética para la relación con el mundo animal no humano. La necesidad de una nueva actitud. En R. Villarroel (Ed.), Ética aplicada (págs. 121-150). Santiago de Chile: Editorial Universitaria.

-Frías, R. (2004). Bioética en el Magisterio de la Iglesia católica. Una selección de textos. Estudios Públicos (93), 317-391.

-Heidegger, M. (2000). Carta sobre el bumanismo. Madrid: Alianza.

-Heidegger, M. (2007). Conceptos fundamentales de la metafísica. Mundo, finitud, soledad. Madrid: Alianza. 
-Juan Pablo II (1987). Encíclica 'Sollicitudo rei socialis' (30 de diciembre). En M. Correa Casanova (Ed.) (2013), Documentos del Magisterio Social Pontificio (págs. 251-290). Valparaíso: Publicaciones del Pontificio Seminario Mayor San Rafael.

-Juan Pablo II (1991). Encíclica 'Centesimus annus' (1 de mayo). En M. Correa Casanova (Ed.) (2013), Documentos del Magisterio Social Pontificio (págs. 291337). Valparaíso: Publicaciones del Pontificio Seminario Mayor San Rafael.

-Juan Pablo II (1995). Encíclica 'Evangelium vitae' (25 de marzo). En A. Sarmiento (Ed.) (1996), El don de la vida. Documentos del Magisterio de la Iglesia sobre Bioética. Madrid: BAC.

-Juan Pablo II (1998). Encíclica Fides et ratio (14 de septiembre). Santiago de Chile: San Pablo.

-Linzey, A. (1996). Los animales en la teología. Barcelona: Herder.

-Milano, A. (1996). Persona in teología. Alle origine del significato di persona nel cristianesimo antico. Roma: Piemme.

-Pascual, R. (Ed.) (2005). Evolución, cruce de caminos de la ciencia, la filosofía y la teología. Roma: Studium.

-Pikaza, X. (2006). Antropología bíblica. Tiempos de gracia. Madrid: Sígueme.

-Popper, K. (1985). Büsqueda sin término. Una autobiografía intelectual. Madrid: Tecnos.

-Prieto, L. (2008). El hombre y el animal. Nuevas fronteras de la antropología. Madrid: BAC.

-Ratzinger, J. (2002). Introducción al Cristianismo, Salamanca: Sígueme.

-Rawls, J. (1995). Teoría de la justicia. Buenos Aires: FCE.

-Regan, T. (1983). The Case of Animal Rights. California, University of California Press.

-Ruse, M. (2008). Darwin. Buenos Aires: Katz.

-Sarmiento, A. (Ed.) (1996). El don de la vida. Documentos del Magisterio de la Iglesia sobre Bioética, Madrid: BAC.

-Sgreccia, E. (2000). Manuale di bioetica. (vol. I). Milano: Vita e Pensiero.

-Spaemann, R. (2000). Personas. Acerca de la distinción entre 'algo' y 'alguien'. Navarra: EUNSA.

-Singer, P. (2003). Desacralizar la vida bumana. Madrid: Cátedra.

-Singer, P. (2011). Liberación animal. Madrid: Taurus.

-Tettamanzi, D (2002). Diæionario di bioetica. Milano: Piemme.

Sumario: Introducción. El problema y el método; I Parte: 1. La filosofía y sus formas; 2. El darwinismo y la ciencia moderna; II Parte: 1. El Magisterio católico en el debate en torno a la cuestión animal; 2. Características de su intervención; Consideración final; Referencias. 